\title{
Endoscopy-Assisted Placement of a Crosby Capsule by a New Method: Results of a Preliminary Study
}

Jejunal biopsy using a Crosby capsule provides a sample of more villi in a row, and can be interpreted more easily, when compared with endoscopic duodenal biopsies (1). In addition, the duodenal mucosa, a common site of inflammation, may be difficult to interpret (2). The Crosby capsule can be placed in the jejunum blindly, with control radiography or fluoroscopic guidance. These methods have some disadvantages, such as loss of time and significant failure rates with the blind method, and the need for radiological screening devices and radiation-associated risks in the latter (3). We therefore introduced a new endoscopic method for the same purpose (4).

After the patient's throat has been anesthetized with $10 \%$ lignocaine and midazolam sedation has been given, a Crosby capsule with a loop of knotted thread tied at its neck (Figure 1) is inserted into the stomach, with the endoscope following it. Inside the stomach, it is easy to catch the thread using a biopsy forceps, and the capsule and endoscope are then advanced together up to the third part of the duodenum (Figure 2). There, air is aspirated and the endoscope is removed, while the tubing of the capsule is held with one hand so that it does not come out as well. After this, the patient walks about for about 15 minutes, and a jejunal biopsy is obtained.

This method was tested with informed consent in 40 adult patients (mean age $43 \pm 14$ years, 26 men, 14 women). It took six minutes on average to place the capsule in the third part of the duodenum in 38 cases. In two cases, the pylorus could not be traversed due to an antral malignancy in one patient and solid food in the other. Of the 38 successful procedures, jejunal biopsy was obtained in 37 $(97.3 \%)$. No complications occurred, and the patients tolerated the procedure well. Endoscopic assistance allowed a diagnosis of aphthous ulcerations and flattened valvulae of the duodenum in six patients, esophagitis in nine, antral gastritis in six, and antral malignancy in one patient.

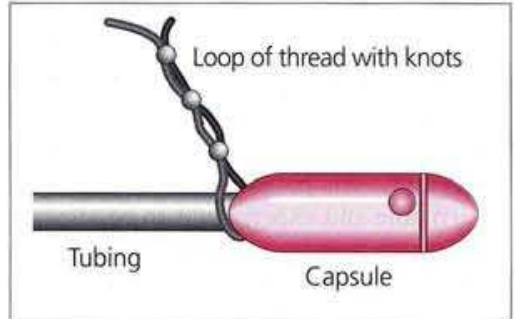

Figure 1: Crosby capsule with a loop of knotted thread tied at its neck.

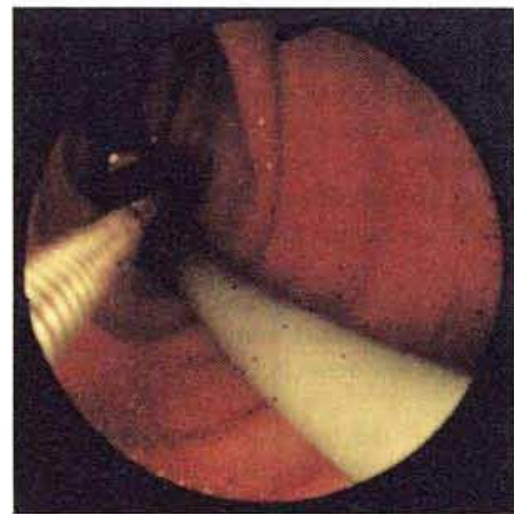

Figure 2: The capsule in the second part of the duodenum, with the biopsy forceps holding the thread.

The new method is particularly helpful in patients in whom upper endoscopy is planned in addition to jejunal biopsy, and when radiological screening is not available or dangerous. It also saves time in comparison with the other, non-endoscopic methods.

G. Öksüzoglu, B. Sivri, A. Kadayifci, Y. Bayraktar, S. Arslan, G. Tatar, H. Şimşek, M. Arslan, B. Kayhan

Dept. of Gastroenterology, Hacettepe Medical School, Ankara, Turkey 


\section{References}

1. Scott BB, Jenkins D. Endoscopic small intestinal biopsy. Gastrointest Endosc 1981; 27: 162-7.

2. Sullivan PB, Marianne BP, Neale G. Endoscopic capsule biopsy of the small intestine. J Pediatr Gastroenterol Nutr 1988; $7: 544-7$.

3. Granditsch G, Deutsch J, Tsarmaklis G, Kletter K. Exposure to $\mathrm{X}$-rays during small bowel biopsies in children. Eur J Pediatr 1981; 137: $165-9$
4. Öksüzoğlu G. Endoscopy-assisted placement of a Crosby capsule [letter]. Gastrointest Endosc 1995; 41: 82.

Corresponding Author

G. Öksüzoğlu, M.D.

Bayindir Tip Merkezi

06520 Eskişehir Yolu

Ankara, Turkey

Fax: +90-312-2850733 